\title{
Analisis dan perancangan e-bisnis dalam budidaya dan penjualan ikan cupang menggunakan metodelogi overview.
}

\author{
Rachmat Destrana1, M. Didin Rafiudin ${ }^{2}$ \\ Universitas Muhammadiyah Tangerang/Fakultas Teknik, \\ Program Studi Informatika \\ Jalan Perintis Kemedekaan 1/33 Cikokol Kota Tangerang TLP.55793251, 55772949, 55793802 \\ e-mail : rachmat.destriana@gmail.com
}

\begin{abstract}
Abstrak
Perkembangan teknologi, sosial, dan budaya menimbulkan banyak perusahaan yang didirikan untuk mencapai tujuan tertentu dalam memenuhi kebutuhan manusia. Electronic Business atau E-Business adalah suatu kegiatan transaksi, jual-beli, bisnis yang dilakukan melalui perangkat elektronik atau dengan internet sehingga perusahaan dapat langsung berinteraksi dengan costumer, supplier maupun rekan bisnis. Ikan cupang merupakan Salah satu ikan hias yang mudah dipelihara, budi daya ikan cupang tidak perlu tempat yang luas dan modal yang besar, bisa dilakukan sebagai usaha rumahan. Salah satu keistimewaan ikan cupang adalah daya tahannya, dia sanggup hidup dalam tempat atau lingkungan air yang minim dan minim oksigen, bisa dipelihara dalam toples kecil tanpa aerator, kemampuan ini didapat kerena ikan cupang memiliki rongga labirin seperti pada paru paru manusia, labirin tersebut bisa membuatnya bertahan hidup di lingkungan yang miskin oksigen. Maka dari itu bisnis ikan cupang ini bisa kita jadikan bisnis online (e-bisnis) agar bisnis ikan ini lebih meningkat dan dapat mencapai pasar global.
\end{abstract}

Kata Kunci: Perancangan, Sistem Informasi, ebisnis, ikan

\begin{abstract}
Technological, social, and cultural developments cause many companies to be established to achieve certain goals in human needs. Electronic Business or E-Business is an activity of transactions, buying and selling, business conducted through electronic devices or the internet so that companies can directly interact with customers, suppliers and business partners. Cupang fish is one of the easy-to-maintain ornamental fish, Cupang fish cultivation does not need a large area and large capital, it can be done as a home-based business. One of the features of Cupang fish is its durability, it is able to live in a place or water environment that is minimal and lack of oxygen, can be maintained in small jars without an aerator, this ability is obtained because cuppang fish have a labyrinth cavity as in the human lung, the labyrinth can make it survive in an oxygen-poor environment. Besided that we can make this cuppang fish business online (e-bisnis) so that the fish business will increase and reach the global market.
\end{abstract}

Kata Kunci: Development, Information system, ebisnis, fish 


\section{PENDAHULUAN}

Pada zaman modern saat ini dituntut segala sesuatu harus cepat dan tepat. Hal ini dikarenakan semakin bertambahnya jumlah populasi penduduk di dunia saat ini yang terus bertambah. Perkembangan teknologi dan pembangunan juga meningkat sangat pesat, tentunya hal tersebut mempengaruhi pola hidup di masyarakat. Sebuah perusahaan mulai dari bidang jasa maupun manufaktur juga harus mampu memberikan pelayanan yang sangat cepat serta yang terbaik untuk memenuhi keinginan dari masyarakat yang memerlukan pelayanan yang cepat.

E-business memungkinkan suatu perusahaan untuk berhubungan dengan sistem pemrosesan data internal dan eksternal secara lebih efisien dan fleksibel. Salah satu contoh dari e-business misalnya pembelian barang secara online dan pembelian hewan khusus yang memang di perbolehkan di perjual belikan secara online. Tujuan implementasi e-business adalah mendukung efisiensi dan integritas pengola an data sumber daya manusia, keuangan, supply chain management atau logistic management. Selain itu juga berfungsi sebagai sarana komunikasi dan informasi bagi public dan stakeholder lainnya dengan berbasiskan internet, sistem ini dapat diakses di mana saja sesuai dengan hak akses yang telah ditentukan.

Ikan cupang merupakan Salah satu ikan hias yang mudah dipelihara, budidaya ikan cupang tidak perlu tempat yang luas dan modal yang besar, bisa dilakukan sebagai usaha rumahan,

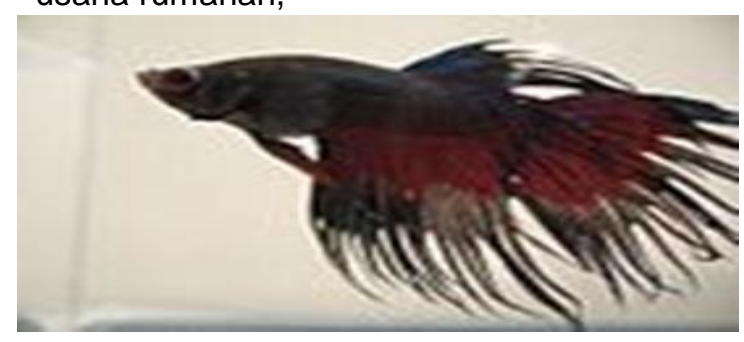

Gambar 1. Ikan Cupang

Salah satu keistimewaan ikan cupang adalah daya tahannya, dia sanggup hidup dalam tempat atau lingkungan air yang minim dan minim oksigen, bisa dipelihara dalam toples kecil tanpa aerator, kemampuan ini didapat kerena ikan cupang memiliki rongga labirin seperti pada paru paru manusia, labirin tersebut bisa membuatnya bertahan hidup di lingkungan yang miskin oksigen.

Maka dari itu bisnis jual beli ikan cupang ini bisa kita jadikan bisnis online (ebisnis) agar bisnis ikan ini lebih meningkat dan dapat mencapai pasar gelobal.

\section{Identifikasi Masalah}

Berdasarkan latar belakang diatas, maka identifikasi masalah yang dirumuskan sebagai berikut:

1. Banyaknya masyarakat yang tidak mengetahui betapa mudahnya budidaya ikan cupang.

2. Jika ingin membeli ikan cupang maka masyarakat harus pergi ke toko ikan cupang yang akan memakan cukup banyak waktu, karena jarang sekalli atau memang belum ada ikan cupang ini yang di jual secara online.

\section{Rumusan Masalah}

Berdasarkan identifikasi masalah diatas, maka rumusan masalah yang hasilkan sebagai berikut:

"Bagaimana cara merancang system informasi dan penjualan ikan cupang secara online, agar masyarakat dapat lebih mudah membeli dan mengetahui cara budidaya ikan cupang"

\section{Batasan Masalah}

Untuk menghindari terlalu luasnya pembahasan yang akan diteliti maka penulis membatasi permasalahan hanya pada pengolahan data informasi dan penjualan ikan cupang. Meliputi pendataan modal penjualan ikan cupang, Pendataan Konsumen, Transaksi penjualan, pembelian ikan cupang, dan informasi budidaya ikan cupang.

\section{Tujuan Masalah}

\begin{tabular}{|c|c|}
\hline $\begin{array}{l}\text { Tujuan } \\
\text { ntukan } \\
\text { gkatkan }\end{array}$ & $\begin{array}{l}\text { penelitiar } \\
\text { pemasaran } \\
\text { jumlah }\end{array}$ \\
\hline
\end{tabular}


mempermudah masyarakat membeli dan mengetahui informasi budidaya ikan cupang.

\section{Konsep Dasar Sistem}

Menurut Moekijat dalam Prasojo (2011:152), "Sistem adalah setiap sesuatu terdiri dari obyek-obyek, atau unsur-unsur, atau komponen-komponen yang bertata kaitan dan bertata hubungan satu sama lain, sedemikian rupa sehingga unsur-unsur tersebut merupakan satu kesatuan pemrosesan atau pengolahan yang tertentu"

Terdapat dua kelopmpok di dalam pendefinisian system yaitu:

1. Mendefinisikan sestem sebagai sebuah jaringan kerja dari prosedur-prosedur yang saling berkaitan, berkumpul bersama untuk melakukan sebuah aktifitas atau untuk menyelesaikan suatu sasaran tertentu.

2. Mendefinisikan system sebagai kumpulan dari elemen-elemen yang berinteraksi untuk mencapai suatu tujuan tertentu.

\section{Konsep dasar informasi}

Definisi dari informasi adalah data yang diolah menjadi bentuk yang lebih berarti bagi yang menerimannya.

Menurut Raymond Mcleod informasi adalah data yang telah diolah menjadi bentuk yang memiliki arti bagi si penerima dan bermanfaat bagi pengambilan keputusan saat ini atau mendatang. Secara umum informasi dapat di definisikan sebagai hasil pengolahan data dalam bentuk yang lebih berguna dan lebih berarti bagi penerimannya, Sumber dari informasi adalah data.

Data adalah kenyataan yang menggambarkan suatu kejadian-kejadian dan kesatuan nyata. Kejadian-kejadian adalah sesuatu yang terjadi pada saat tertentu.

Data merupakan bentuk yang masih mentah, belum dapat bercerita banyak sehingga perlu diolah lebih lanjut. Data diolah melalui suatu metode untuk menghasilkan informasi

Data yang diolah melalui suatu model menjadi informasi, penerima kemudian menerima informasi tersebut, membuat suatu keputusan dan melakukan tindakan, yang berarti menghasilkan suatu tindakan yang lain yang akan membuat sejumlah data kembali.

\section{Konsep dasar system penjualan}

Sistem Penjualan adalah sistem yang melibatkan sumberdaya dalam suatu organisasi, prosedur, data, serta sarana pendukung untuk mengoperasikan sistem penjualan, sehingga menghasilkan informasi yang bermanfaat bagi pihak manajemen dalam pengambilan keputusan.

Dalam konteks aktualisasi pendapat di atas, perencanaan strategis/penjualan tentu perlu menganalisis tuntutan perkembangan lingkungan strategis, yang langsung atau tidak langsung bersentuhan dengan pelaksanaan tugas pokok dan fungsi analisis yang dimaksud inidapat dilakukan dengan pendekatan analisis S-WOT, yakni analisis terhadap factor-faktor lingkungan internal dan lingkungan eksternal.

\section{Analisis SWOT}

Menurut Pearce dan Robinson
(2013),
AnalisisS-WOT adalah metode untuk
mengidentifikasi berbagai faktor secara
sistematis untuk merumuskan strategi
berdasarkan logika yang dapat memaksimalkan
kekuatan (trengths) dan peluang (Opportunities)
dan secara bersamaan dapat meminimalkan
kelemahan (Weakness) dan ancaman (Threats)
jadi analisis S-WOT membandingkan antara
faktor eksternal peluang dan ancaman dengan
faktor internal kekuatan dan kelemahan.

\section{Analisa Value Chain}

Analisa value chain dilakukan untuk memetakan seluruh proses kerja yang terjadi dalam organisasi menjadi dua kategori aktivitas, yaitu aktivitas utama dan aktivitas pendukung.mengacu pada dokumen organisasi yang menyebutkan tugas dan fungsi setiap unit kerja berdasarkan pengamatan yang dilakuka nterhadap proses kerja yang terjadi di masingmasing unit kerja.

\section{Metodologi Overview}

\section{A. Begin}

Salah satu Perusahaan yang belum terlalu besar. Kegiatan usaha di bidang penjualan, yaitu ikan cupang, lkan cupang sangat populer 
dijadikan ikan hias dengan alasan tampilan ikan mungil yang sangat menarik dan benntuknya yang unik,juga daya tahannya yang luar biasa, bisa bertahan di akuarium dalam jangka waktu yang lama meski tidak dilengkapi dengan aerator atau sirkulator udara.

Sebagai ikan hias, ikan cupang terbagi ke dalam beberapa jenis diantaranya

cupang halfmoon dengan sirip juga ekornya yang lebar menyerupai bulan separuh, cupang crowntail (atau dikenal juga dengan nama ekor mahkota) dengan ekor pun sirip yang hampir mirip dengan sisir. cupang double tail atau ekor ganda

cupang plakat halfmoon, dan cupang giant dengan ukuran yang bisa menyentuh angka $12 \mathrm{~cm}$. Ukuran ini termasuk raksasa dalam kelas ikan cupang

\section{B. Diagnose}

Salah satu keistimewaan ikan cupang adalah daya tahannya, dia sanggup hidup dalam tempat atau lingkungan air yang minim dan minim oksigen, bisa dipelihara dalam toples kecil tanpa aerator, kemampuan ini didapat kerena ikan cupang memiliki rongga labirin seperti pada paru paru manusia, labirin tersebut bisa membuatnya bertahan hidup di lingkungan yang miskin oksigen.

Makadari itu bisnis ikan cupang ini bisa kita jadikan bisnis online (e_bisnis) agar bisnis ikan ini lebih meningkat dan dapat mencapai pasar gelobal

Tidak usah takut jika ikan mati saat pengeriman dan perjalanan yang jauh kemampuan ikan cupang ini dapat bertahan di tempat yang minim oksigen jadi tidak akan ada masalah

\section{ANALISIS SWOT}

\section{- Factor kekuatan (strength)}

1. potensi lahan masih luas

2. teknik budidaya mudah
3. banyak di cari orang karena bentuknya yang indah dan perawatan yang mudah

4. memberikan penjelasan mengenai pemeliharaan dan perawatan yang baik

- factor kelemahan (weakness)

1. intensifikasi lahan kurang

2. aktifitas kelompok kurang

3. harga relative murah

- factor kesempatan (opportunity)

1. biasa di jadikan usaha sampingan atau part time dengan modal yang kecil

2. pengembangan lahan

3. pengembangan jejaring kerja sama

- factor ancaman (threat)

1. persaingan yang semakin ketat

2. kondisi cuaca tidak bias di perediksi

3. harga ikan cupang yang tidak setabil D. Develop

Strategi jenis ini menganggap pasar sebagai keseluruhan, jadi perusahaan hanya memperhatikan kebutuhan secara umum. Produk yang dihasilkan dan dipasarkan biasanya hanya satu produk saja dan berusaha menarik konsumen dengan satu rencana pemasaran saja. Strategi pemasaran ini melayani kebutuhan beberapa kelompok tertentu dengansatu jenis produk tertentu pula. Jadi produsen atau perusahaan menghasilkan produk yang berbeda sesuai dengan segmen pasar. Dengan kata lain produsen dan perusahaan menawarkan berbagai variasi produk yang disesuaikan kebutuhan dan keinginan kelompok konsumen yang berbeda dengan program pemasaran yang khusus diharapkan tigkat keberhasilan penjualan pada masing-masing segmen tersebut tercapai.

\section{E. Define}

Peluang untuk mengembangkan bisnis secara global Jaringan banyaknya outlet pelanggan dapat diekplorasi untuk menjual produk selain ikam cupang, bisnis ikan cupang ini bisa kita jadikan bisnis online (e_bisnis) agar bisnis ikan ini 
lebih meningkat dan dapat mencapai pasar gelobal.

\section{F. Determine}

Ikan cupang merupakan Salahsatu ikan hias yang mudah dipelihara, budidaya ikan cupang tidak perlu tempat yang luas dan modal yang besar, bisa dilakukan sebagai usaha rumahan.

Ikan cupang biasanya di jual di toko/kios ikan hias, penggemmar ikan cupang bukan hannya ada di dalam negri tetapi sudah mendunia sehingga ikan cupang dapat di pasarkan di internet. Dengan cara tersebut maka potensi pemasaran ikan cupang lebih efektip

\section{G. Design}

Toko Ikan Cupang Hias dan Aduan

\section{Home}

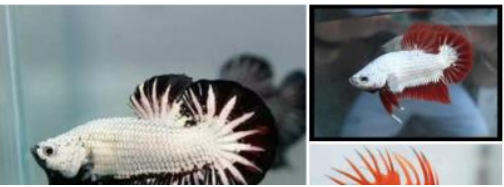

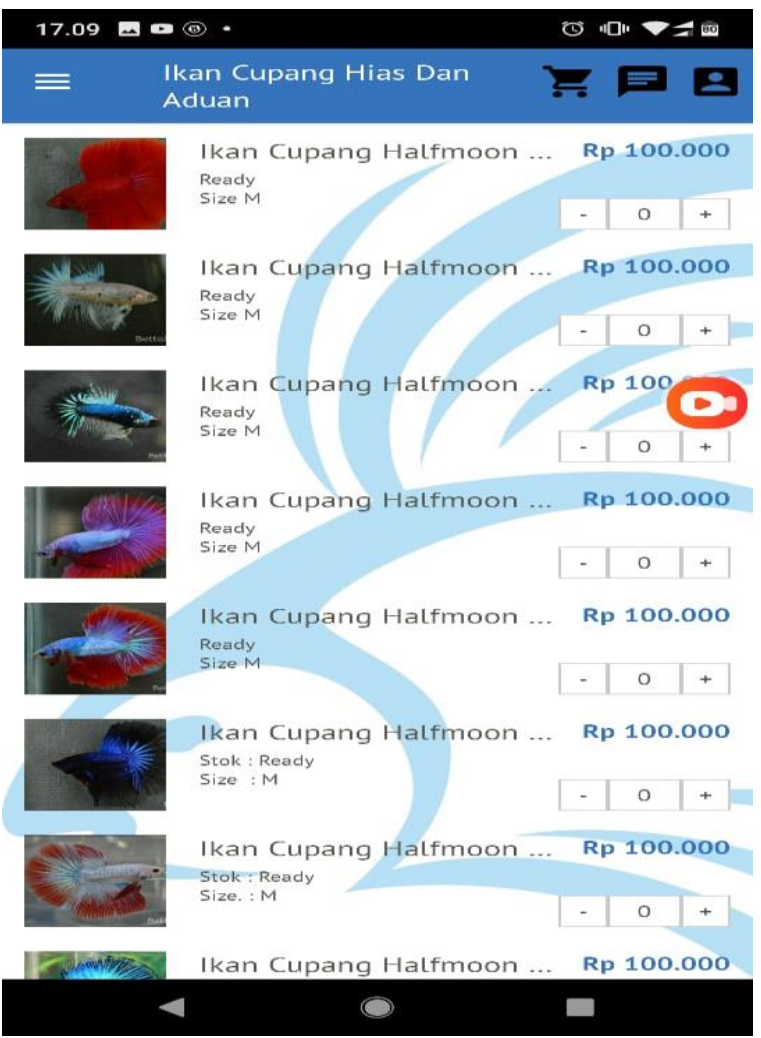

\section{H. Deliver}

Ikan cupang sangat populer dijadikan ikan hias dengan alasan tampilan ikan mungil yang sangat menarik dan benntuknya yang unik,juga daya tahannya yang luar biasa, bisa bertahan di akuarium dalam jangka waktu yang lama meski tidak dilengkapi dengan aerator atau sirkulator udara.

Bedasarkan keterangan di atas ikan cupang sangat baik jika di jadikan E-business karena ikan tersebut memiliki daya tahan yang kuat dan perawatan yang mudah juga bentuk yang indah, dengan strategi yang baik dan perawatan yang baik juga dengan peromosian lewat iklan di internet dan peromosian web atau aplikasi yang kita racang akan sangat berpengaruh pada tigkat pemasaran ikan cupang ini

Sebagai ikan hias, ikan cupang terbagi ke dalam beberapa jenis diantaranya 
cupang halfmoon dengan sirip juga ekornya yang lebar menyerupai bulan separuh, cupang crowntail (atau dikenal juga dengan nama ekor mahkota) dengan ekor pun sirip yang hampir mirip dengan sisir. cupang double tail atau ekor ganda

cupang plakat halfmoon, dan cupang giant dengan ukuran yang bisa menyentuh angka $12 \mathrm{~cm}$. Ukuran ini termasuk raksasa dalam kelas ikan cupang.

- Cara menentukan indukan cupang jantan yang baik

1. Pilih ikan yang sering berenang di bawah ataupun melayang ditengah permukaan. Jangan pilih ikan yang sering berenang pada permukaan air. Hal itu menandakan bahwa ikan itu dalam kedaan tidak sehat.

2. Pilihlah ikan yang memiliki warna cerah. Meskipun ikan itu berwarna gelap (hitam) pilihlah warna yang mengkilat. Karena itu merupakan ciri pejantan tangguh.

3. Ikan cupang jantan haruslah lincah. Jika ingin mengetahui lincah atau tidak ikan itu, coba dekatkan dengan cupang jantan lain. Maka akan terlihat nantinya.

4. Setelah mencapai usia delapan bulan. Dapat ditandai dengan ukuran yang melebihi ukuran empat sentimeter, atau melihat pangkal ekor yang kekar.

5. Sering membuat gelembung busa di permukaan air.

6. Gerak gerik yang genit ketika melihat cupang betina.

- Cara menentukan indukan betina yang baik

1. Ikan betina memiliki warna pudar dan gerakannya tidak lincah. Ikan ini cenderung lebih sering diam.

2. Memiliki bentuk fisik yang bagus.

3. Memiliki warna yang cemerlang serta memiliki sirip yang tegas.

4. Pilih ikan cupang betina yang memiliki matang telur. Betina yang matang telur dapat diketahui dari perutnya yang buncit dan dibagian perut bawahnya (dekat dengan sirip dasi ikan) ada semacam bintik bintik putih.

5. Mencapai usia 6 bulan. Ditandai dengan perutnya yang gendut

- Media dan alat peijahan ikan cupang

1. Dapat menggunakan wadah berupa aquarium, gentong atau ember/baskom plastik sebagai tempat pemijahan. Jangan gunakan tempat yang terlalu lebar.

2. Isi dengan air yang telah diendapkan dengan kedalaman antara $10 \mathrm{~s} / \mathrm{d}$ $15 \mathrm{~cm}$. Untuk pemijahan idealnya adalah 25 derajad Celcius.

3. Siapkan media pijah (substrat), bisa berupa tanaman air seperti Java Moss, daun ketapang kering, potongan styrofoam atau serabut rafia atau lembaran plastik bening tempat si jantan membuat busa/sarang untuk meletakkan telur.

4. Jangan lupa berikan sedikit garam ke tempat dimana akan dilakukan pemijahan ,untuk meminimalkan tumbuhnya jamur yang dapat menyerang ikan cupang.

- Cara pemijahan

1. Masukkan jantan dan betina yang akan dikawinkan ke wadah pemijahan yang telah disiapkan dan biarkan selama 1 hari

2. Dalam tempo antara 2 hingga 8 jam si jantan akan membangun busa pada substrat yang akan digunakan sebagai tempat bercumbu dan bulan madunya.

3. Jika dalam waktu 2 hari masih tidak ada telur, maka segera pisahkan pasangan tersebut

4. Proses pernikahan akan terjadi selama kurang lebih 2-3 hari

5. Pada saat pemijahan tubuh si jantan akan melilit dan menyelubungi tubuh induk betina membentuk huruf "U" dengan ventral saling berdekatan sampai betina mengeluarkan telur yang segera dibuahi oleh sperma si jantan.

6. . Pada umur 5 minggu barulah siap untuk dilakukan Pendederan

7. Pada usia 4 hingga 6 minggu barulah mulai terbentuk organ labirinnya 
8. Setelah lewat umur 6 minggu pemberian diet makanan mulai variatif, jentik nyamuk (cuk), kutu air dan bloodworm

9. Lakukan penggantian air sebanyak $30 \%$ dengan cara siphon atau membuka drain/valvenya

10. Umur 7 hingga 8 minggu mulai dapat disortir jantan atau betina.

11. Umur 10 hingga 12 minggu dapat disortir berdasarkan grade A, B, atau C

12. Pilih anakan yang kualitas baik atau super, dan diletakkan mereka dalam aquarium terpisah (soliter)

- Cara memperlakukan hasil pemijahan (anak)

1. Dengan meletakkan tanaman air pada wadah pemijahan

2. Secara naluri pula mereka dengan atraktif akan menyerang sesuatu yang bergerak

3. Pada saat burayak berumur 3-4 hari dapat diberikan vinegar eels (belut cuka)

4. Setelah burayak berumur 1 minggu dapat diberikan pakan kutu air saring atau BBS (Baby Brine Shrimp)/Artemia yang telah dikultur

5. Pemberian kutu air dan Artemia bisa dilanjutkan hingga burayak berumur 3 minggu

\section{Discuss}

- Analisis usaha

Analisis usaha budidaya ikan cupang dengan membeli 8 pasang indukan ikan cupang antara lain :
- Biaya investasi

\begin{tabular}{|ll|l|}
\hline 1 Indukan cupang 8 pasang @ Rp & Rp 1.600 .000 \\
\hline 200.000 & Akuarium & Rp 280.000 \\
\hline $3 \begin{array}{l}\text { Botol bekas air mineral } \\
1 \text { liter 1.600 20 } 20 \times 25 \mathrm{~cm} \text { ' 8 } \\
\text { buah @ Rp 35.000buah @ Rp 500 }\end{array}$ & Rp 800.000 \\
\hline $4 \begin{array}{l}\text { Pembuatan kolam semen 1 m3 8 } \\
\text { buah@ Rp120.000 }\end{array}$ & Rp. 960.000 \\
\hline Total & Rp 3.640.000 \\
\hline
\end{tabular}

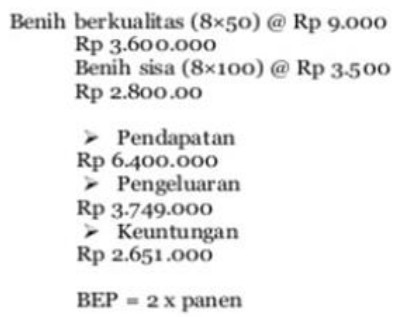

- Tindakan yang di lakukan untuk lebih mengembangkan usaha

Hasil analisis usaha di atas merupakan awalan untuk memulai usaha ikan cupang ini maka dari itu perlu adanya tindak lanjutan guna mengembangkan hasil usaha mecapai pasar gelobal

Dengan setrategi di atas tentu kita sudah mengetahui yaitu dengan meningkatkan hasil pemijahan untuk memperbanyak indukan yang baik dan mendapat hasil anakan yang lebih banyak dan juga baik.

Dari hasil analisa Metodologi Overview di atas kita sudah mengetahui dengan miningkatkan penjualan dan promosi melalui internet sangat berpengaruh besar terhadap kemajuan suatu usaha, maka dari itu penulis menyarankan untuk tingkatkan usaha ikan cupang ini agar mencapai pasar gelobal.

- Rincian Biaya peningkatan peromosi dan penjuaal melalui internet

- Biaya pembuatan Website Hosting Rp 144,500. Menggunkan domain.com

- Biaya hosting perbulan Rp 144,500 (Rp. 1.734.000/tahun) 
- Biaya promosi, Instagram, Youtube, Tergantung dari seseorang yang mempunyai akun tersebut mohon maaf bila penulis belum bias merincihkannya karena biasanya biaya promosi melalui sosmed itu berbeda-beda tergantung dari tingkat viewers akun dan juga orang yang memiiliki akun tersebut.

\section{KESIMPULAN}

\begin{abstract}
Dari hasil penelitian yang sudah dilakukan dan disusun dalam jurnal ini, diharapkan dalam melakukan budidaya dan penjualan ikan cupan dapat dilakkan dengan menerapkan konsep ebisnis dalam kegiatan operasional maupun budidaya ikan cupang sehingga dapat meningkatkan kualitas dan kuanttas dalam pengembangan ikan cuang. Semoga jurnal ini dapat memberi manfaat bagi peneliti khususnya dan pembaca pada umumnya. Dan mohon maaf apabila masih banyak kekurangan di dalam jurnal ini. Penulis berharap kepada pembaca untuk memberikan kritik dan saran yang bersifat membangun kepada penulis demi perbaikan jurnal yang akan datang.
\end{abstract}

\section{DAFTAR FUSTAKA}

[1] Pearce dan Robinson (2013), AnalisisSWOT Moekijat dalam Prasojo (2011:152), Definisi system.

[2] Raymond Mcleod "informasi"

[3] https://jualikancupanghiasdanaduan.wordpr ess.com/

[4] Sanjaya, Ridwan. 2009. Cara Kilat Mempunyai Website Sendiri - Lanjutan. Jakarta: PT. Elex Media Komputindo.

[5] Jogiyanto, H.M. 2005. Analisis dan Desain Sistem Informasi, Edisi Kedua. Yogyakarta: ANDI.

[6] Susanto, Azhar. 2004. Sistem Informasi Manajemen Konsep dan Pengembangannya. Bandung: Lingga Jaya.

[7] Andi, Kristanto. 2003. Perancangan Sistem Informasi dan Aplikasinya. Yogyakarta: Gava Media.

[8] https://www.slideshare.net/nidachofiya/anali sis-swot-ikan-cupang

[9] Ahmadi, Candra dan Dadang Hermawan. 2013. E-Business dan E-Commerce. Yogyakarta : CV. Andi Offset.

[10] Sutabri, Tata. 2012. Konsep Sistem InformasiYogyakarta.
[11]Diani Susanti, Mustahal ;, Pramu Sunyoto, USAHA PEMBENIHAN IKAN HIAS CUPANG (Betta splenders) DI KABUPATEN SERANG. 